\title{
Ergonomics Program Management in Tucuruí Hydropower Plant using TPM Methodology ${ }^{1}$
}

\author{
R. M. Santos, ${ }^{\text {a, }}$, A. C. Sassi ${ }^{\text {, }}$, B. M. Sác, S. A. Miguez ${ }^{\text {d }}$ and A. A. Pardauil ${ }^{\mathrm{e}}$ \\ ${ }^{a}$ Health Pillar, Eletrobras Eletronorte, 21, Fausto Guimaraes St., Vila Permanente, Tucuruí, Pará, Brazil \\ ${ }^{b}$ Strategic Management Committee, Eletrobras Eletronorte, 13, Portugal St., Tucuruí, Pará, Brazil \\ ${ }^{c}$ Strategic Management Committee, Eletrobras Eletronorte, 21, Espírito Santo St, Vila Permanente, Tucuruí, \\ Pará, Brazil \\ ${ }^{\mathrm{d}}$ Ergosy Consulting, Ergosys, 555 João duque St, Campinas, São Paulo, Brazil \\ ${ }^{\mathrm{e}}$ Superintendência de Geração Hidráulica, Eletrobras Eletronorte, 21, Fausto Guimaraes St., Vila Permanente, \\ Tucuruí, Pará, Brazil
}

\begin{abstract}
This paper aims to present the benefits achieved in the ergonomics process management with the use of the TPM methodology (Total Productive Maintenance) in Tucuruí Hydropower Plant. The methodology is aligned with the corporate guidelines, moreover with the Strategic Planning of the company, it is represented in the TPM Pillars including the Health Pillar in which is inserted the ergonomics process. The results of the ergonomic actions demonstrated a $12 \%$ reduction over the absenteeism rate due to musculoskeletal disorders, solving $77,0 \%$ of ergonomic non-conformities, what favored the rise of the Organizational Climate in $44,8 \%$, impacting on the overall performance of the company. Awards confirmed the success of the work by the achievement of the Award for TPM Excellence in 2001, Award for Excellence in Consistent TPM Commitment in 2009 and more recently the Special Award for TPM Achievement, 2010. The determination of the high rank administration and workers, allied with the involvement/dynamism of Pillars, has assured the success of this management practice in Tucuruí Hydropower Plant.
\end{abstract}

Keywords: TPM, Hydropower Plant, Health Pillar

${ }^{*}$ Corresponding author. E-mail: rejane@eln.gov.br 


\section{Introduction}

Property of Eletrobrás Eletronorte, Tucuruí Hydropower Plant, located about $400 \mathrm{~km}$ far from Belém in Pará state in the city of Tucuruí, is the largest hydropower plant in matters of $100 \%$ Brazilian generation $(8,370 \mathrm{MW})$, as the Itaipu plant is binational. The plant went into commercial operation in 1984 and has become one of the greatest engineering works in the world. The Tucuruí Plant has been acting in the electricity business, under the status of utility company. Its core competency is the availability of electricity generation capacity to the National Interconnected System, through the operation and maintenance of Hydraulic Generating Units. Tucuruí plant has a workforce of approximately 500 people to operate and maintain itself.

The strategic guideline of the organizations conducts their actions to achieve market growth, with the development of specific software's, implementation of international standards, processes automation and use of robots. Nevertheless the facilities and equipments are not sufficient to entrust the triumph of those organizations.

In this perspective the journey of Tucuruí plant for Business Excellence started in 1993 with the implementation of the program of quality and productivity. Eletrobras Eletronorte is always in a continuous search for improved management of its processes; in 1999 it began the implementation of the TPM methodology (Total Productive Maintenance), with consultation of JIPM (Japan Institute of Plant Maintenance), resulting in the attainment of the Award for TPM Excellence - Category A, in 2001. TPM was developed in the 70s in Japan and is a tool to improve the quality of products and services [1]. It is instituted on redesigning and improving the business structure from the restructuring and progress in the performance of people and equipment, involving all hierarchical levels and changing the organizational posture. The TPM is a management tool that provides increased productivity by reducing losses.

The implementation of TPM in the company was crucial in attaining new proofs of acknowledgement for it, such as: Prêmio Qualidade da Gestão Pública (Public Management Quality Award) in 2002; Prêmio Qualidade do Trabalho (Labour Quality Award) in the period from 2000 to 2008; certification of financial processes and achievement of NBR ISO 9001, conjointly with NBR ISO 14001, regarding the Environment, in the period from 2007 to 2009. And yet, the recognition by the Fundação Nacional da Qualidade (National Quality Foundation) under the criteria of Leadership, People and Society in the years 2009 and 2010, and the SMMT / JIPM that granted the plant the Award for Consistent TPM Commitment in 2009.

In 2010, it is highlighted the fact that Tucuruí has been rendered the head office of the Eletrobras Eletronorte generation process, becoming responsible for the managing of a Superintendence consisted of three generating plants and establishing itself as the mother plant for TPM methodology promotion in the company and expanding this role when leading the dissemination of the methodology also to various stakeholders in its production chain and making use of the TPM methodology as a fundamental practice to the achievement of Business Sustainability. In the same year, Tucuruí delve into the quest for the Special Award of JIPM, being the only power company in the world to achieve this level of recognition. These awards were only made possible because the implementation of the TPM methodology is aligned with the Strategic Plan of Eletrobras Eletronorte.

The writings point that TPM is composed by 8 basic pillars that must be followed and worked during implementation for the results to be achieved [2], however, in Tucuruí, the methodology was structured proactively onto 11 pillars, they are: Business Sustainability, Focused Improvement, Autonomous Maintenance, Planned Maintenance, Early Management, Quality Maintenance,Office, Training and Development, Safety, Health and Environment. Each pillar has a specific objective and contributes to achieving the general objective of the TPM in Tucuruí, defined as: Increase the availability index (ID) and reduce the operational cost of energy.

As an object of this study, we present how Health Pillar contributes to the achievement of the TPM objective in promoting the overall health for all employees, thus providing a healthy and safe work environment through the Ergonomics Program. It is noteworthy that the Health Pillar coordinates the treatment of ergonomic hazards through the Ergonomics Program and deploys new improvements aimed at eliminating the risks and / or minimize them using the company's learning system, the infinite looping.

Furthermore, it is noteworthy that the focus of Health Pillar is the human factor, based as strongly in the evolution of technical training and as strongly in optimizing the work done by people. Re-education and pro-activity for the prevention actions are great allies to the success of organizations during the 21 th century. 


\section{Total Productive Maintenance Methodology}

The TPM is a methodology that emerged in Japan in the 70's in a company related to the Toyota group, and quickly became part of the organizational culture of this great company and also of its suppliers and affiliates. Later other companies have adopted it in industry segments of serialized processes [3].

To Nakajima [2], "TPM can improve the overall effectiveness of the facilities through an organization based on respect for human creativity and the general participation of all employees of the company."

According to Suzuki [4], there was a rapid growth of TPM in assembly industries, particularly companies in the automotive and household appliances, as well as among manufacturers of semiconductors and electronic components. It was also introduced in continuous process industries (petroleum refining, chemical, steel, food, gas, ceramic, cement, paper, pharmaceutical, metallurgical, glass, tires and publishing).

Again, to the same author "there are three strong reasons for the TPM popularity in Japan: the expressive range of outstanding results in operations; improving the factory environment and the possibility of obtaining PM Distinguished Plant Prize (PM Prize)".

According to Ribeiro [5], "In Brazil, many companies have adopted TPM, based on some principles of teamwork and autonomy as well as a continuous improvement approach to prevent breakdowns." Ribeiro also notes that "some companies operating in Brazil have consolidated the deployment process, including some recognized by the award of JIPM. They are: Yamaha, GM, Alcoa, Pirelli Cabos, Pirelli Pneus, Andréas Stihl, Alumar, Texaco do Brazil, FIAT, Copene, Ford, Azaléia, Marcopolo, Multibras, Editora Abril, Votorantin Celulose e Papel, Eletronorte, Gessy Lever, Tilibra, Cervejaria Kaiser, Ambev, etc.".

According to Mirshawka and Olmedo [6], "TPM is a maintenance program which involves the set of all employees of the organization, from senior management, until the workers of the production line." Each author uses different words and expressions to define this program, but the important thing is that it is a management program that has been widely deployed in several companies around the world.

TPM has clear objectives, which must be followed in order to achieve the goals. Those objectives are: Zero Break, Zero Defect, Zero Accident, Zero Loss, Zero Pollution and Total Quality. As to reach those objects, TPM relies itself on implementation steps. Campos et al. apud Carvalho, Pereira \& Turrioni [7], list four steps for the TPM implementation, unfolded into a total of 12 steps,

Below the pillars of TPM methodology are discussed.

\subsection{TPM Pillars in Tucurui Hydropower Plant}

For TPM to be possible there is a methodology based on eight principles, known as the eight pillars of TPM. As mentioned earlier Tucuruí plant set along with JIPM the formatting of the eleven pillars as shown in Figure 1.

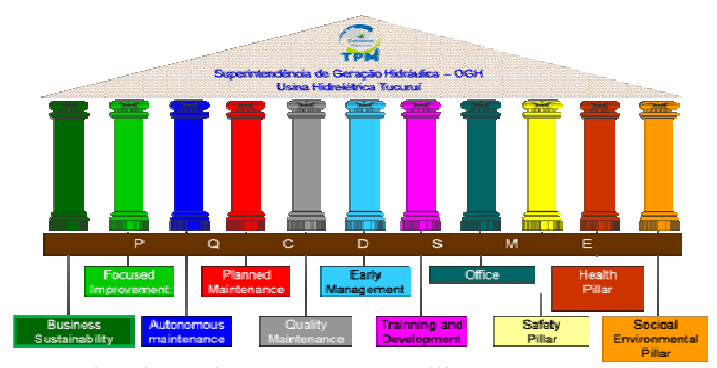

Figure 1. Eletrobras Eletronorte's TPM Pillars

Each pillar of TPM is correlated with the Strategic Plan, Policies and Objectives of Eletronorte, based on the BSC (Balanced Scorecard), as shown in Figure 2. It should be noted that ergonomics is more specifically addressed in the Health pillar under the perspective of People and Learning with the corporate objective of "Increasing the productivity of the workforce" and under the Early Management pillar with the corporate objective of "Making business processes more efficient," and it could be inserted into the other nine pillars.

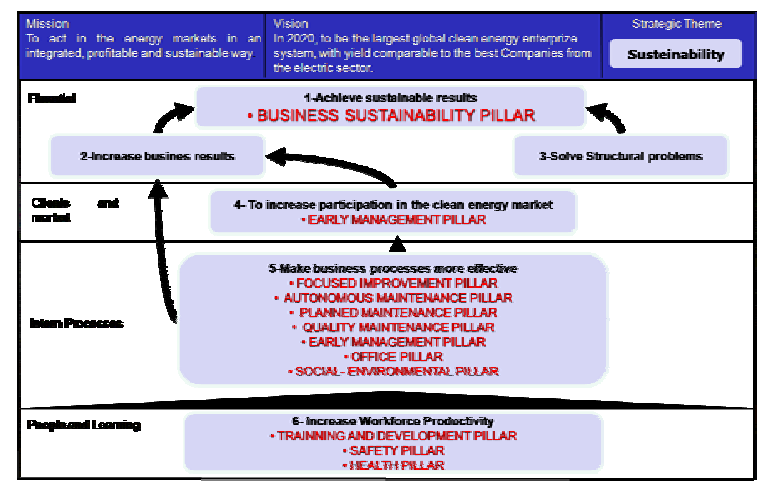

Figure 2. Strategic Plan and correlating pillars of TPM 


\subsection{Definition of Pillars}

\subsubsection{Business Sustainability Pillar}

Its premise is to share responsibilities with a focus on the concept of social growth, on income generation and especially on encouraging the vocation of each municipality, thereby providing the involvement and empowering people for effective sustainable growth with respect to the environment and future generations.

\subsubsection{Focused Improvement Pillar}

The activities of Focused Improvement intend, fundamentally, the identification and the elimination of all losses and, consequently, obtain growth of the effectiveness of equipments, systems and productive processes, through the utilization of techniques of analysis and improvement (Kaizen), promoting substantial alterations that will ultimately lead to achieving maximum productivity limits.

\subsubsection{Autonomous Maintenance Pillar}

This pillar is geared towards developing operators to be able to take care of small maintenance tasks, thus letting the qualified maintenance personnel to focus on higher added-value activity and technical repairs. Operators are responsible for maintaining their equipment to prevent deterioration.

\subsubsection{Planned Maintenance Pillar}

It is the grouping of all maintenance activities carried out by maintainers, i.e., by employees of the maintenance team, with aim at:

- Improving equipment availability;

- Improve the maintenance efficiency;

- An optimal level of loss reduction;

- Achieve zero accidents;

- Develop maintenance techniques that enable a reduction in intervention time and involved costs;

- improved maintenance structure and management;

- Support activities of operation teams.

\subsubsection{Quality Maintenance Pillar}

This pillar is dedicated to the clients' delight through highest quality result of defect free manufacturing. The focus is on eliminating non-conformities in a systematic way, also on Focused Improvement. QM Activities serve to establish equipments conditions that hinder any quality defect, based on the basic concept of perfect equipment maintenance to maintain the perfect product quality. The conditions are verified and measured in the historical series and those values that are held within standard range will be the ones to avoid defects. The transitions of measured values is watched in order to foresee the possibilities of occurring defects and subsequently take defensive measures before hand.

The Quality Maintenance Pillar in Tucuruí plant has the main objective of monitoring the quality of product, electrical energy, by monitoring indices referring to the quality of the same.

\subsubsection{Early Management Pillar}

This pillar seeks alternatives to develop new products and invest in the acquisition of more efficient equipment in order to take preventive action, thus anticipating situations of breakdowns and losses. The goal in TPM is to drastically reduce the time from development to full production and get the "vertical start-up" (a quick start of operation, defect-free - on the first attempt).

\subsubsection{Training and Development Pillar}

This pillar seeks to structure the actions of education and training in a way to enable the increase of knowledge, skills development and behavioral changes, in constant search for a team with domain over its equipment and with proactive attitudes.

\subsubsection{Office Pillar}

The identification and conceptual dissemination of the processes of the Office aims to empower employees to visualize these processes in an integrated manner and, from this focused integrated view on processes, solidified through a methodology conceived on the philosophical principles of TPM, they will establish standards, procedures and indices to permit evaluation, analysis and continuous improvement of these processes. So, all this is to ensure continued support from the office to activities of operating, maintaining, marketing and expansion of the company.

\subsubsection{Safety, Health and Environment Pillar}

The Safety, Health and Environment Pillar comprises a set of actions linked to policies and programs instituted in the company, being a part based on legal aspects relating to Occupational Safety and Health and Environment, whereas for the other part the focus is on assistance policies and programs linked the health of employees in seeking to maintain the level of zero accidents, physical and mental health of em- 
ployees, environmental management, with improved quality of life [8].

The Ergonomics Program, since 2001, originated with the implementation of the TPM in 1999 and it aims to contribute to the achievement of the objectives of Health Pillar. The program is supported by the Ergonomics Committee - COERGO - covering several actions, a few of them are: Ergonomic Analysis of Work through weekly inspections, Workplace Calisthenics, Postural School, Relaxation Time; Functional Therapeutic Academy. The objectives of the Ergonomics Program in Tucuruí are:

- Adapt the environment and all its constituents and jobs to our workers;

- Enhance the well-being and overall system performance;

- Be compliant to the Brazilian Legislation (NR17 of the Ministry of Labour and Employment);

- Prevention of work related disorders;

- Render the ergonomics moment the access to the integration of different sectors: Supplies, Occupational Safety and Health, Human relations and foremost the Production sector;

- Humanize the work processes

- Making the working environment the integration source;

- Add value to the end-product by humanizing our production.

To conduct TPM process in Tucuruí plant it was initially established a TPM secretariat with full dedication to the dissemination of the techniques of the program, which reports directly to the Superintendent of the plant and acts as an internal consultant assisting various departments in the implementation of the TPM.

\section{Methodological Aspects}

Among the eleven pillars that guide the management of TPM in Tucuruí, this article focuses on the application of Health Pillar, which focuses on the use of techniques aiming to improve the efficiency of health management. For the development of the work, it was used methods such as gathering of technical literature and references, direct observation, unstructured interview and quali-quantitative methods.

For this study, it was necessary to use data collected directly from the pillar management for the development of TPM methodology.
Regarding the type of research, Vergara [9] classifies as to ends and means. As for ends, using descriptive and explanatory research, explanatory one clarifies some factors occurring in the company, plus, it assumes the descriptive research as the basis for its explanations. On the other hand, it is used the descriptive one due to the part of the literature research about the matter and for the description of TPM methodology in the studied company.

The research strategy adopted in this work is the case study. According to Godoy [10], the case study has become the preferred strategy when researchers seek to answer the questions "how" and "why" certain phenomena occur. As for the means this study is considered a case study, because it describes the management of Health Pillar using the TPM methodology in loco, through the theoretical presentation of this methodology and the results obtained in a real case.

\section{Case Study: Health Pillar}

Health pillar has the general objective of promoting the quality of life with integral health for all employees and their families.

Fernandes [11] conceptualizes Quality of Working Life - QWL - as a dynamic and contingent management of physical, technological and sociopsychological factors that affect the culture and renew the organizational climate, reflecting the wellbeing of the worker and the firm productivity.

The pillar is also responsible for occupational health management in Tucuruí, it is structured from 1999 with the implementation of the TPM in the company. Initially, the Health pillar was conducted in conjunction with the Safety pillar, afterward it was dismembered in 2003, from that period until the present day the pillar underwent several improvements in its management process. It currently has an organizational structure consisting of coordinator and surrogate members and others with various specialties of health care area as a doctor, physiotherapist, nurse, social assistance worker, physical education teachers, administrative assistant and nutritionist, with further support from members of the HR (human resources) and IT (information technology). The pillar is connected to the TPM promotion secretariat of Tucuruí Hydropower Plant.

According to Campos [7], one of the most important concepts of quality programs is the premise that the only thing that improves is the thing that can be 
measured, and therefore, it is a must to measure to improve. Thus, it is necessary to systematically evaluate the satisfaction of the company professionals, as in this self-awareness process, internal opinion polls are an important tool to detect employees' perceptions about the factors affecting the quality of life and work organization.

To structure the Health pillar initially, it was held a historical survey identifying critical points related to the health of employees. To address the identified problems, specific objectives, indicators and goals to be achieved. were defined.

The actions developed in the Health pillar are deployed in the Master Plan with a schedule for 04 years, divided by areas of expertise in the company, points out:

\subsection{Loss Tree}

In order to conduct a study on losses related health costs in Tucuruí, along with Focused Improvement pillar, whose main objective is to eliminate losses related to benefits management where health-care costs have a direct impact.

The study of the Loss Tree and Costs Tree provides a detailed analysis of health care costs in Tucuruí, then, as to implement improvements in the Ergonomics Program to reduce costs of absenteeism related to musculoskeletal disorders and costs with ergonomically correct adaptations/adjustments of the plant.

\subsection{Occupational Health}

In order to make the management of the Occupational Health and Medical Control Program (PCMSO), with actions aimed at prevention and control of employees' health through periodic medical examination, immunization and awareness campaigns, nutritional assessments, check-ups with specialists ( breast cancer specialist and urologist) and control of five health risk factors (BMI - body mass index, blood pressure, triglycerides, glucose and cholesterol);

\subsection{Ergonomics}

Companies develop strategies to manage their business and it could not be different when we think of ergonomic actions programs.
We may consider that the ergonomics actions programs in companies are "key" to sow the crop of ergonomic education amongst people [12].

The reflections generated by these programs bring to the surface workers' awareness imbuing processes related to their beliefs and solutions over the problem of protecting, promoting health and improving quality of life if it involves work or even personal activities [13].

In this pillar, the focus of actions is to perform the prevention of work-related musculoskeletal disorders performing: Ergonomic analysis of the workplace, Ergonomic Corrections/Adjustments, Workplace Calisthenics, Relaxation Time, Medical treatment of musculoskeletal injuries; Postural School, Functional Therapeutic Academy and Ergonomics Committee.

\subsection{Psychosocial.}

In order to carry out actions aimed at improving the Organizational Climate of the company, Psychosocial care was given to employees; it were analyzed the results and proposals regarding the surveys on quality of life, stress level and preparation for retirement.

It should be noted that the occupational, ergonomics and psychosocial medicines perform their actions together so that their goals are achieved, therefore reducing the impact on the Loss Tree of Tucuruí plant.

\section{Ergonomics Program Management}

The planning actions of the ergonomics program begins at Excellence Workshop held annually in Tucurui Strategic Planning for deployment. Strategic planning is based on developing a clear institutional mission, feasible goals and objectives, a perfect strategy and proper implementation [14]. In ergonomics making the perfect strategy is not easy due to the dynamism of science technology. The actions developed in the program are deployed using the tool $5 \mathrm{~W} 2 \mathrm{H}$ and accompanied by performance indicators and actions with their respective targets.

Each action follows the planning and execution of improvement cycles made based on the infinite looping which means: Learning and Innovation. The "infinite looping of learning and innovation" or simply "Infinite Looping" is shown in Figure 3, which was the main method of learning Tucuruí. The infinite looping integrates the principles of TPM and MEG in 
two rounds "PDCA" and "CAPD" complementary, being used both for continuous incremental improvement (kaizen) and cycles for formal

The PDCA cycle, also known as The Stewhart Cycle, Quality Cycle or Deming Cycle, is a methodology that has as its main function to be a diagnosis auxiliary for organizational problem analysis and solving. Few instruments show themselves as effective as this one in the search for improvement, considering that it leads systematic actions that accelerate the achievement of better results in order to assure the survival and growth of organizations [15].

The PDCA Cycle has as main objective to control processes, and it can be used continuously to its management in an organization, establishing control guidelines (quality planning). The CAPDo Cycle is a variation of the PDCA one, in which the data analysis begins with the $\mathrm{C}$ (check), the suggestion to promote process improvement.

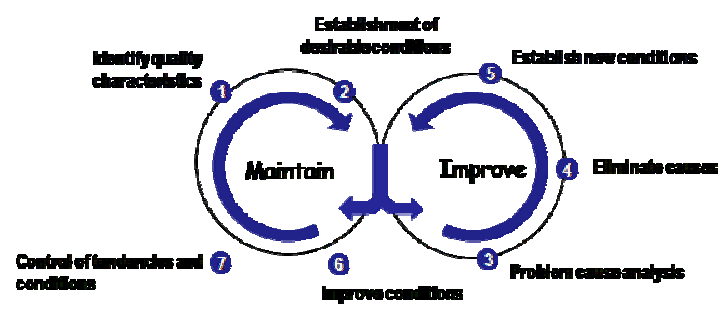

Figure 3 Infinite Looping

As in figure 3, the innovation and learning process through the "Infinite Looping" follows these steps:

Daily Management (Do):

1 - Identify the current situation: At this stage there is the state of quality, identifying the existing rules, assessing the degree of compliance by identifying ergonomics non-conformities. As an evaluation method is used Ergonomics Work Analysis protocols. Still at this stage the Losses is established for losses and costs related to health plans, diseases and penalties.

2 - Restore to the initial condition to restore the initial state, evaluate results: On this step the themes of ergonomic improvements in Tucuruí Power Plant are identified. The following are priority issues for improvement according to the risks that the area will be developed in conjunction with the Ergonomics Committee. Then the plan is established to improve and track the results. It should be noted that improvements are recorded in the database of Focused Improvement Pillar.
6 - Management Improving: This step is related to the management of the Master Plan of the Ergonomics Program where actions are deployed for the year in question. There is also the management of ergonomic improvements registered in the database in order to keep it updated. The management of the implementation of improvements is accompanied by a computerized system and through the ergonomics committee monthly meetings. For the implementation of improvements in Tucurui all managers are involved and give the support needed for them to be held under the company's ergonomics guidelines. Replication of ergonomic improvements occurs according the processes needs. Also in this step is the managing of the key indicators system from the Ergonomics Program and the implementation of blocking actions when necessary.

7 - Track conditions: Make sure that the rules are visually verifiable and that they will be fulfilled. This step is formed by the critical analysis of the Ergonomics Program and of its results.

Improvement (Check, Action, Plan):

3 - Analyze the causes: In this step improvement teams are formed and use cause analysis techniques, such as: Whys Analysis, FMEA, brainstorming, Ishikawa, 5W2H matrix. Tucuruí also uses the ergonomics analysis according to: Moore e Garg, NIOSH, OCRA, REBA, Sue Rodgers.

4 - Develop improvements: investigation of all factors, restore and improve the defects, check results. This step is carried out the planning and implementation stages of ergonomic improvements as well as testing and validation.

5 - Establish the new conditions: review standards. This step is the standardization in accordance with the new ergonomic condition and training where necessary for the stakeholders. When there is equipment with the same characteristic horizontal replication occurs, and when appropriate patent process is used to register ergonomics improvements .

According to the Infinite looping Methodology to manage Daily Activities, we follow these steps: 1. Identify the current situation, 2 . Restore to the initial condition 6. Improving the conditions and 7. Control conditions. To achieve the improvement, or learning improvement following steps: 3. Analyze causes 4 . Develop improvements and 5. Establish the new conditions. 


\section{Results}

As qualitative results it can be observed the consolidation of a health structure to promote actions based on results, which are monthly monitored and retrofeeds the program for the implementation of improvements after analysis using quality tools and through the use of the Infinite looping, thus contributing to the achievement results more quickly. Table 1 presents the results of actions performed in the Ergonomics Program, it emphasizes its results.

Table 1

Ergonomics Program Results

\begin{tabular}{|c|c|c|c|c|c|c|c|}
\hline \multirow{2}{*}{\multicolumn{2}{|c|}{ KEY PERFORMANCE INDICATORS }} & \multirow{3}{*}{$\begin{array}{c}\text { UN } \\
\boldsymbol{*}\end{array}$} & \multicolumn{3}{|c|}{ ACHIEVED } & \multirow{2}{*}{$\frac{\text { COAL }}{2011}$} & \multirow{2}{*}{ BeIIR } \\
\hline & & & 208 & 2009 & 2010 & & \\
\hline $\mathrm{ABS}_{\mathrm{D}}$ & $\begin{array}{l}\text { Illneas Absenteoism } \\
\text { Index }\end{array}$ & & 2,62 & 2,40 & 2,08 & $\mathbf{2 , 0 0}$ & \\
\hline$A B S_{0 s t}$ & $\begin{array}{l}\text { Museulo-ekolotal } \\
\text { dilseases Index }\end{array}$ & \% & 11,3 & 15,2 & 13,4 & 2,00 & \\
\hline ISNC $_{\text {Eg }}$ & $\begin{array}{l}\text { Non-eompllanes } \\
\text { Egoonemie Solutions } \\
\text { Index }\end{array}$ & $\mathbf{x}$ & 50,2 & 6,5 & $\pi, 0$ & 95,0 & \\
\hline Isco & Climato Satisfaction & ж & 83,6 & 84,26 & - & 24,5 & \\
\hline CPS & $\begin{array}{l}\text { Health Insurance } \\
\text { Costs }\end{array}$ & un & 2.59 & 2.87 & 2,50 & 258 & \\
\hline ID & $\begin{array}{l}\text { Enerog generation } \\
\text { Avallability Index }\end{array}$ & * & 20,78 & 90,56 & 02,50 & 84,0 & \\
\hline
\end{tabular}

As previously mentioned, the result of Pillar health, specifically the ones of the Ergonomics Program contributed to achieving the overall objective of the plant achieved after the $3 \%$ increase on electricity generation availability in the last 3 years. As a result of the consolidation of all these results, the Japanese Institute of Plant Maintenance recognized Tucuruí Hydroelectric Plant with The 2010 TPM Special Award.

\section{Conclusion}

Based on this study, it is possible to verify the significant contribution of Health Pillar, once the integration of TPM Pillars and a pleasant working environment are essential to Tucuruí Power Plant performance. The prevention activities, based on the rehabilitation of people and team work development, allow the application of the methodology with low investment and high capacity of financial return [16]. It was also observed that currently, the company uses intensively the concepts of TPM, adopting them in all company's sectors and developing a strong corporate culture based on the principles of this methodology. This is the result of the inclusion of the TPM methodology of Strategic Planning Tucuruí and of its deployment involving learning opportunities through the application of the infinite Looping. The TPM methodology contributed significantly in the managing of the ergonomics program and with the implementation of Pillar Health, contributing to Company's development, Organizational Climate improvement and having direct impacts on the quality of life of employees, thus improving overall plant performance.

\section{References}

[1] Tavares, Lourival. Administração moderna da manutenção. Rio de Janeiro: Novo Polo, 1999.

[2] Nakajima, S. Introdução ao TPM, Tradução de Mario Nishimura, IMC Internacional Sistemas Educativos Ltda, São Paulo, 1989.

[3] Tonelotto Jr., W. O Facilitador e o TPM. São Paulo: Loss Prevention, 2005

[4] Suzuki, Tokutaro. New Directions for TPM. Massachusetts: BookCrafters, 1992.

[5] Ribeiro, H.: Total Productive Maintenance Manutenção Produtiva Total. São Paulo: EPSE, 2004.

[6] Mirshawka, V. \& Olmedo, N.L. TPM à Moda Brazil eira. São Paulo: Makron Books, 1994.

[7] Campos, Vicente Falconi. TQC - Controle de qualidade total. 2.ed. São Paulo: Bloch Editores, 1992.

[8] Manual de Regulamentos e Métodos do TPM na Eletronorte, Tucuruí, 2000.

[9] Vergara, S.C. Projetos e relatórios de Pesquisa em Administração. 4 ed. São Paulo: Atlas, 2003.

[10]Godoy, A.S. (1995) - Pesquisa Qualitativa: Tipos Fundamentais. Revista de Administração de Empresas, v.35, n. 3, p. 25-35.

[11] Fernandes (1996)

[12] Vidal, M. C. R. Ergonomia na empresa: útil, prática e aplicada. 2ed. Rio de Janeiro: Ed.Virtual científica, 2002. 282p.

[13] Oliveira, A. J.; Fagundes, T. L. Q. Educação e saúde: o trabalhador enquanto sujeito de sua saúde. IN: KIEFER, C.; FAGÁ, I.; SAMPAIO, M. R. (org). Trabalho-Educação-Saúde. São Paulo: Fundacentro, 2001, p.119-32. 
[14] Kotler, P.; Hayes, T.; Bloom, P. N. Marketing de Serviços profissionais. 2ed. Barueri: Ed. Manole, 2002. 511p.

[15] Quinquiolo, J. M. Avaliação de um Sistema para Melhorias Implantado na Área de Carroceria de uma Linha de Produção Automotiva. TaubatéSP: Universidade de Taubaté, 2002.
[16] Moreira, D.C. Estudo de Caso: Experiência de Tucuruí na Gestão da Manutenção Utilizando TPM. TCC de Pós Graduação de Engenharia de Produção - Facinter, 2011 